\title{
Preliminary Work With Tanier (Xanthosoma spp.) Hybridization in Puerto Rico ${ }^{1}$
}

\author{
Francisco L. Jordán Molero ${ }^{2}$ \\ ABSTRACT \\ Plants were easily obtained from seeds of fruits resulting from crosses \\ between tanier cultivars Kelly, Vinola and Blanca del País. Protogyny appears \\ to be responsible for self-incompatibility. Seed set is abundant with good \\ germination in 2 weeks. Growth and development are very rapid and vigorous \\ as compared to that of parental cultivars.
}

\section{INTRODUCTION}

Tanier, also known as yautía and cocoyam (Xanthosoma spp.) is a very important food crop in tropical and subtropical areas. It is an excellent source of carbohydrates and minerals, ranking in this respect, equally with sweet potato, yams, and Irish potatoes (1). In recent years, the demand for taniers has increased considerably in the U.S.A. mainland mainly due to increased populations of Cubans and Puerto Ricans (5). In Puerto Rico, the area planted to taniers has decreased from 3.2 thousand hectares in 1960 to around 2.4 thousand in 1970. Annual production has decreased from 27,500 to 14,500 tons from 1950 to 1976 mainly due to "mal seco" $(1,2)$, a serious disease that is spreading rapidly in all local growing areas. González Villafañe and Espinet Colón (1) reported that $87 \%$ of the farmers blamed "mal seco" for the low yields of taniers.

Breeding work with taniers has been neglected throughout the years mainly due to irregular or no flowering, protogyny, and lack of interest in major producing areas. The National Academy of Sciences in their publication "Underexploited Tropical Plants with Promising Economic Value" (4), reports: "Great effort has been devoted to introducing and adapting the potato to the lowland tropics, while indigenous tropical root crops have been largely neglected ... Cocoyams have received little attention by researchers ... If agronomists select high-yield, good quality cultivars, and develop a technology for their intensive cultivation, cocoyams could become a major tropical food crop."

This paper presents the results of recent work conducted in Puerto Rico in an effort to develop a technique suitable to the production of Xanthosoma hybrids.

\footnotetext{
${ }^{1}$ Manuscript submitted to Editorial Board November 22, 1978.

${ }^{2}$ Professor and Director, Department of Horticulture, College of Agricultural Sciences, University of Puerto Rico, Mayagüez Campus, Mayagüez, P.R.
} 


\section{MATERIALS AND METHODS}

Observations were made on flowering behaviour of a tanier collection of 25 species and varieties at the College Farm of the University of Puerto Rico, Mayagüez Campus.

A technique reported by the author with Caladium (3) was tried with taniers. The procedure involved removing about one third of the spathe on each of two sides leaving the pistillate zone partially uncovered. This operation was performed a day before the spathe opened when the stigma was receptive but the pollen was still unshed. Pollen from the male parent was collected with a camel-hair brush and applied to the pistillate zone. With this technique, crosses were performed between cultivars Vinola and Kelly, Blanca del País and Kelly, and Kelly and Kelly.

Infructescences were soaked in water, crushed, and forced through an 8-mesh sieve. Seeds were recovered as they passed through the sieve with the washing water. They were planted immediately after extraction in a peat-perlite-vermiculite mixture. When seedlings had 3 to 4 leaves they were transplanted to pots $10 \mathrm{~cm} /$ in diameter containing the same medium used in the seedbed. Plants received a soluble 18-18-18 fertilizer as needed.

Some plants were transplanted to $40 \%$-shade house while others were transferred to the field under full sun growing conditions.

\section{RESULTS AND DISCUSSIONS}

Flowering was very irregular with only four cultivars flowering in a collection of twenty-five species and varieties. Kelly flowered freely while Blanca del País, Vinola and Rascana, flowered only sparsely. The flowering period began in late September and continued through February in a very irregular pattern. Plants kept unharvested under field conditions for two years failed to flower even though their main corm enlarged significantly. Cold storage $\left(50^{\circ} \mathrm{F}\right)$ for 90 days did not induce flowering. Use of gibberellic acid appeared to induce flowering, but abnormalities such as absence of pollen, failure of spathe to unfurl, and a significant reduction in foliage were observed.

Fruit setting was very low with only approximately $10 \%$ of flowers setting and maturing fruits. Most flowers that did not set started to deteriorate after the third day from pollination. Fruits ripened at 40 to 50 days when they became soft and the peduncle dried out.

Seeds are very small ( $1.0-1.5 \mathrm{~mm})$, light brown in color, striated, oblong and numbering none to eight per fruitlet. They started to germinate in 10 days (fig. 1), making very rapid growth and attaining more than two meters in height in less than six months when grown under shade. Plants from seeds, under full sun, grew more rapidly than plants from parental 


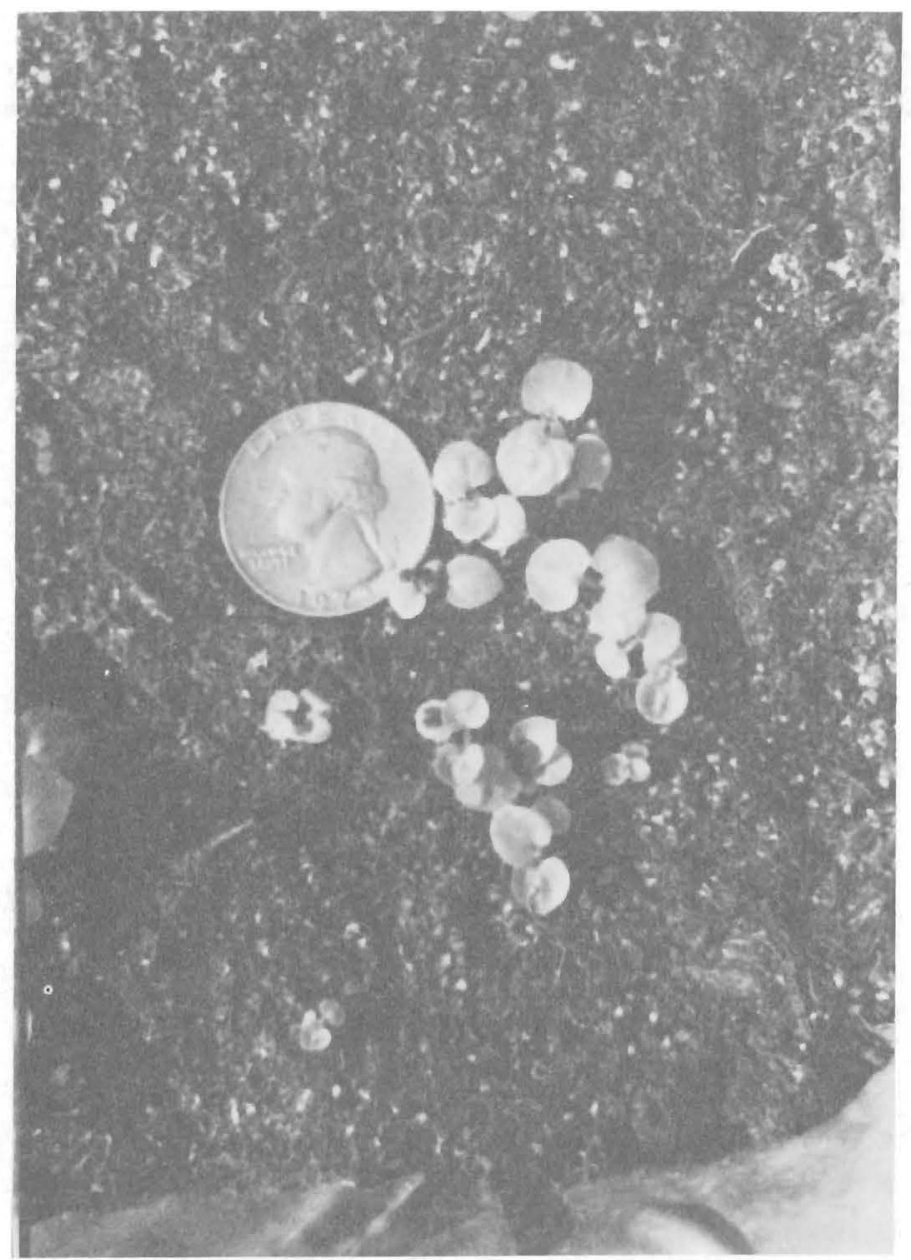

FIG. 1.

cultivars propagated asexually by conventional methods. Even though their planting distance was $1.524 \times 1.219$ meters, leaves of plants between and in the rows merged together in a dense foliage canopy.

Plants under shade flowered up to $40 \%$ when 6 months old. This is a surprisingly high natural flowering rate as compared to that of commercial cultivars, (fig. 2).

Variations in seedlings were observed mainly in number of shoots, color of leaf-stalk, amount of cerosine and leaf size. Seedlings showed an apparent increase in vigor as compared to that of their parents. 


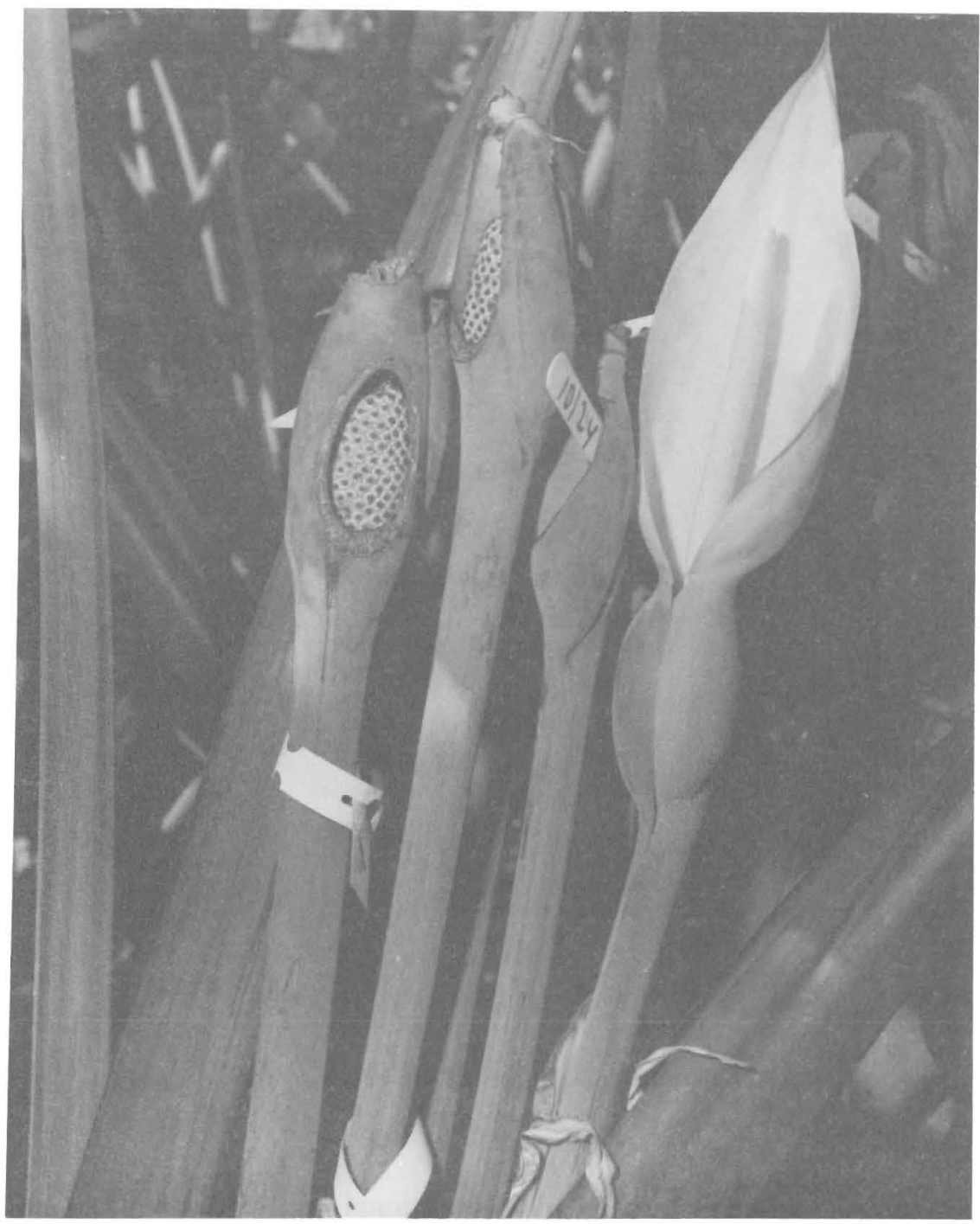

FIG. 2.

\section{RESUMEN}

Cruces entre los cultivares de yautía Kelly, Vinola y Blanca del País produjeron semillas con bastante facilidad. Las plántulas obtenidas crecieron rápidamente demostrando mayor vigor que sus progenitores. Se observa bastante variación en las plantas obtenidas de estos cruces. 


\section{LITERATURE CITED}

1. González Villafañe, E., Espinet Colón, G., 1977. Análisis Económico de la Producción de Yautías, Puerto Rico 1975, Esta. Exp. Agri. Univ. P.R. Bol, 249.

2. Irizarry, H., Câpiel, M., and Acosta Matienzo, A., 1977. Yield performance of 12 tanier cultivars grown with and without irrigation in the east central region of Puerto Rico, J. Agr. Univ. P.R. 61(1): 100-5.

3. Jordán Moloro, F. L., 1956. Breeding of Caladium, Paper presented at the annual meeting of the American Society of Agricultural Sciences. (Abstract Published).

4. National Academy of Sciences. 1975. Underexploited Tropical Plants with Promising Economic Value, Washington D. C.

5. Volin, R. B. and Zettler, F. W., 1976. Seed propagation of cocoyam, Xanthosoma caracu, Koch and Bouche, Hort-Science, II(5):459-60. 